\title{
Access to coronary catheterisation: fair shares for all?
}

\author{
F Kee, B Gaffney, S Currie, D O’Reilly
}

\begin{abstract}
Objective-To determine the effects of patient's sex and area's material deprivation on utilisation rates of coronary catheterisation and angiography in the investigation of ischaemic heart disease.

Design-Retrospective analysis of routinely collected hospital statistics.

Setting-Acute hospitals throughout Northern Ireland.

Subjects-24179 episodes of patients discharged from hospital with a primary diagnosis of ischaemic heart disease and 1270 episodes relating to patients with an underlying diagnosis of ischaemic heart disease who had either coronary catheterisation or angiography.
\end{abstract}

Main outcome measures-Age standardised admission rates for heart disease and age standardised utilisation rates for catheterisation or angiography, or both, for 566 electoral wards ranked by Townsend "deprivation" scores.

Results-Catheterisation-angiography rates in men were over fivefold those of women, ranging from $85 \cdot 5 / 100000 v 16 / 100000$ in patients from "well off" areas to $123 / 100000 v 22 / 100000$ for patients from deprived areas. After admission rates for heart disease were controlled for, the overall rate ratio for women was $0.48(95 \%$ confidence interval 0.38 to 0.60). After differential admission rates for heart disease and other potential clinical confounders were controlled for, the investigation rates of patients from the least and most "deprived" areas were not significantly different (rate ratio 1.04 (0.87 to $1 \cdot 25)$ ).

Conclusion-Although investigation rates were significantly lower in women than in men, further clinical data would be required before labelling this underutilisation as evidence of bias. There was no significant difference in invasive investigation rates for heart disease in areas of varying deprivation or affluence.

\section{Introduction}

Several studies, predominantly from the United States, have shown substantial interpopulation variation in the use of coronary catheterisation and angiography for the investigation of ischaemic heart disease. ${ }^{1-3}$ The prevalence of coronary heart disease and the clinical case mix of patients does not seem to explain adequately the variation in angiography or revascularisation rates described in many of these reports.

Two recent studies from the United Kingdom have suggested that older patients and women have less access to revascularisation services than do younger patients and men. ${ }^{45}$ Elder et al reported a detailed clinical audit which showed that older patients undergoing coronary angiography generally had more severe symptoms than their younger fellows, yet younger patients usually came to angiography having had less intense anti-anginal treatment. On the other hand, Petticrew et al showed that in North West and South West Thames regions men were $50-60 \%$ more likely than women to undergo either angioplasty or bypass surgery. They were, however, unable to distinguish whether this apparent bias operated at the level of investigation or referral for revascularisation.

Though some of the underlying determinants of physicians' discretion can be measured, ${ }^{6}$ other demographic variables of patients may influence the decision to refer for invasive investigation. The chances of undergoing catheterisation in the United States have been shown to be independently related to race and to levels of education and income. ${ }^{78}$ Though discretionary use of angiography is probably less common in the United Kingdom than in the United States, even in a relatively high risk area such as Trent only $49 \%$ of procedures were recently deemed entirely appropriate to the patient's clinical condition, and one in five were frankly inappropriate. ${ }^{9}$

Recent policy imperatives from the Department of Health and Social Services clearly reinforce the need to target health services to those with greatest need. ${ }^{10}$ Given the fact that socioeconomic factors both influence the incidence of ischaemic heart disease and provide independent prognostic information on patients with angina ${ }^{11}$ and that Northern Ireland has possibly the highest rates of material deprivation in the United Kingdom, ${ }^{9}$ we set out, using routinely available data, to investigate whether any sex differences exist in rates of invasive investigation for ischaemic heart disease and to study the relation between population indicators of material deprivation and the utilisation rates of coronary catheterisation and angiography.

\section{Methods}

Data on all patient episodes in Northern Ireland with an associated OPCS IV procedure code K63 (coronary catheterisation) or $\mathrm{K} 65$ (coronary angiography) and an underlying diagnosis of ischaemic heart disease (ICD 410-414) were extracted from the Regional Information Branch database for the years 1990-1 and 1991-2 in respect of all patients aged 20 years or more. (Only two teaching hospitals, both in Belfast, perform these procedures.) The age, sex, underlying diagnosis, and postcode address of all patients were extracted. Postcodes are routinely used by the Department of Health and Social Services to assign the patient episode to one of the 566 electoral wards in the province. The province's total population is 1.5 million.

From a separate file, similar items of information were extracted in respect of all patient episodes (in some 18 acute hospitals) where the primary diagnosis corresponded to ICD 410-414 (acute myocardial infarction, other subacute and chronic ischaemic heart disease, including angina and old myocardial infarction).

By using small area information from the 1991 
census we derived a Townsend deprivation score ${ }^{12}$ for all electoral wards in Northern Ireland. In this manner the areas from which patients came were characterised according to the degree of affluence or deprivation. The score was calculated as the sum of four equally weighted census variables (which were originally chosen explicitly to act as proxies for various aspects of a lack of control over material resources): the percentages of the ward population who are unemployed, have no car, or live in overcrowded housing or who are not owner-occupiers. The resultant scores (ranging from -5.63 to 11.07 ) were ranked, and the wards were then divided by quintiles on the basis of this distribution.

Age standardised utilisation rates (for catheterisation or angiography, or both) were calculated for each fifth, standardised to the world standard population. To adjust for a proxy of "need," these utilisation rates were compared after the different admission rates for ischaemic heart disease (ICD 410-414) of each fifth were allowed for. This was accomplished by using Poisson regression (with EGRET software) after entering terms separately for age and sex. In the regression, age was categorised into five groups: $20-44,45-54,55-64$, $65-74$, and $>75$ years. Adjustment was also made for the frequency of other significant comorbidities, specifically the numbers of deaths and the numbers of patients discharged with primary diagnoses of ischaemic heart disease together with subsidiary diagnoses of heart failure (ICD 428) or diabetes (ICD 250).

\section{Results}

At the end of March 1993 the Department of Health and Social Services hospital episode database held records for the period April 1990-March 1992 on 1270 episodes (for patients 20 years old or more) with an assigned procedure code $\mathrm{K} 63$ or $\mathrm{K} 65$ (where the underlying diagnosis corresponded to ICD 410-414). In addition there were 24179 records for patients with a primary diagnosis of ICD 410-414. Table I shows the numbers of admissions for heart disease and of invasive procedures for each fifth of population. An electoral ward could be assigned to $93 \%$ of those with catheterisation records and to $90 \%$ of those admitted for ischaemic heart disease. The age standardised rates of catheterisation or angiography for men ranged from $85 / 100000$ for the most affluent fifth of population to $123 / 100000$ for the most deprived. The corresponding figures for women were $16 / 100000$ and 22/100000. These and the age standardised admission rates for ischaemic heart disease are shown in the figure. An obvious gradient is apparent, with the most deprived
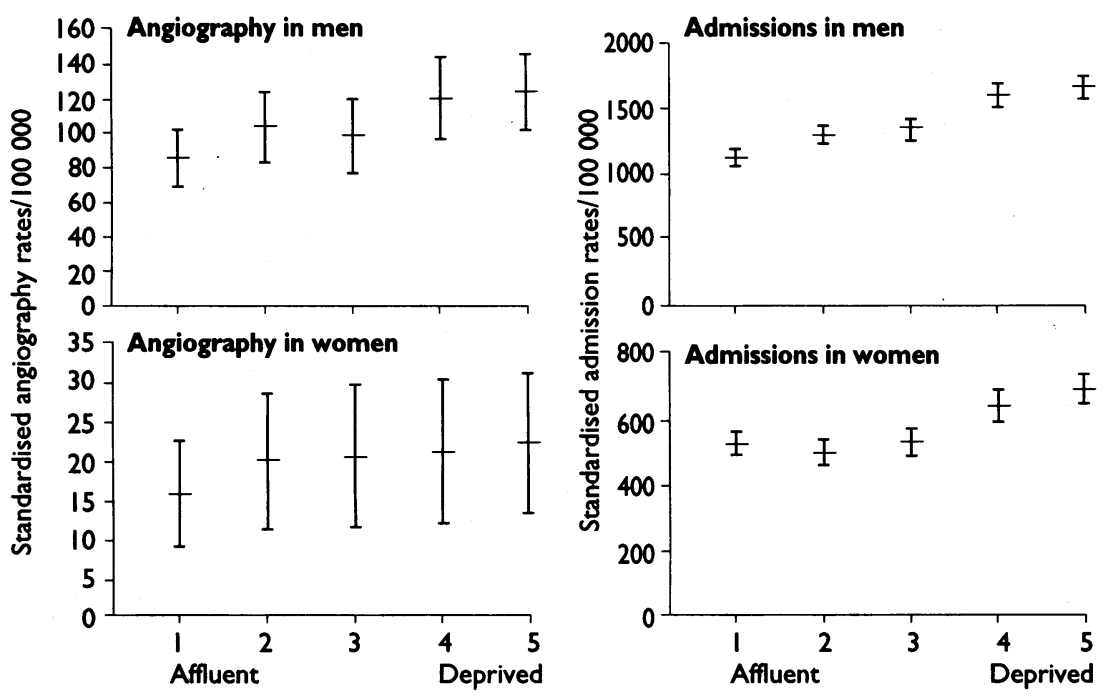

Age standardised rates for angiography and admission for ischaemic heart disease for fifths of electoral wards in Northerm Ireland grouped by Townsend deprivation scores. Bars are means ( $95 \%$ confidence intervals)
TABLE I-Numbers of investigations and admissions for ischaemic heart disease in men and women in Northerm Ireland, 1990-2

\begin{tabular}{|c|c|c|c|c|}
\hline \multirow[b]{2}{*}{ Fifth } & \multicolumn{2}{|c|}{$\begin{array}{l}\text { Catheterisation of } \\
\text { angiography }\end{array}$} & \multicolumn{2}{|c|}{$\begin{array}{l}\text { Admissions for ischaemic } \\
\text { heart disease } \\
\text { (ICD 410-414) }\end{array}$} \\
\hline & Men & Women & Men & Women \\
\hline $\begin{array}{l}1 \text { (Affluent) } \\
\text { Deaths } \\
\text { Heart failure } \\
\text { Diabetes }\end{array}$ & 217 & 46 & $\begin{array}{r}3092 \\
217 \\
267 \\
122\end{array}$ & $\begin{array}{r}2037 \\
242 \\
217 \\
111\end{array}$ \\
\hline $\begin{array}{l}\text { Deaths } \\
\text { Heart failure } \\
\text { Diabetes }\end{array}$ & 208 & 43 & $\begin{array}{r}2829 \\
196 \\
204 \\
106\end{array}$ & $\begin{array}{r}1582 \\
170 \\
165 \\
86\end{array}$ \\
\hline $\begin{array}{l}3 \text { Deaths } \\
\text { Heart failure } \\
\text { Diabetes }\end{array}$ & 173 & 44 & $\begin{array}{r}2688 \\
209 \\
229 \\
129\end{array}$ & $\begin{array}{r}1531 \\
180 \\
170 \\
74\end{array}$ \\
\hline $\begin{array}{l}4 \text { Deaths } \\
\text { Heart failure } \\
\text { Diabetes }\end{array}$ & 205 & 44 & $\begin{array}{r}3082 \\
199 \\
309 \\
122\end{array}$ & $\begin{array}{r}1781 \\
205 \\
206 \\
100\end{array}$ \\
\hline $\begin{array}{l}5 \text { (Deprived) } \\
\text { Deaths } \\
\text { Heart failure } \\
\text { Diabetes }\end{array}$ & 240 & 51 & $\begin{array}{r}3438 \\
270 \\
295 \\
143\end{array}$ & $\begin{array}{r}2130 \\
244 \\
237 \\
101\end{array}$ \\
\hline $\begin{array}{l}\text { Total } \\
\text { Deaths } \\
\text { Heart failure } \\
\text { Diabetes }\end{array}$ & 1043 & 228 & $\begin{array}{r}15129 \\
1091 \\
1304 \\
622\end{array}$ & $\begin{array}{r}9061 \\
1041 \\
995 \\
472\end{array}$ \\
\hline
\end{tabular}

TABLE II-Rate ratios for catheterisation-angiography

Rate ratio ( $95 \%$ confidence interval)

\begin{tabular}{ll} 
Men \\
Women \\
$\begin{array}{l}\text { Deprivation quintilet: } \\
1 \text { (Affluent) }\end{array}$ & 1.0 \\
2 & $0.48(0.38$ to 0.60$)$ \\
3 & 1.0 \\
4 & $1.04(0.87$ to 1.25$)$ \\
5 (Deprived) & $1.04(0.84$ to 1.29$)$ \\
& $1.00(0.83$ to 1.20$)$ \\
\hline
\end{tabular}

*Adjusted for age and admissions for ischaemic heart disease (ICD 410 414), including the proportion of deaths and concurrent secondary diagnoses of heart failure or diabetes.

tAdjusted for age, sex, and admissions for heart disease (ICD 410-414), including the proportion of deaths and concurrent secondary diagnoses of heart failure or diabetes.

populations having the highest utilisation rates for catheterisation and angiography. However, at least for men the gradient for admissions and investigations are comparable.

The differences between the fifths and between the sexes have been more formally assessed by Poisson regression (table II). After age and admissions for heart disease were standardised, women clearly had lower investigation rates than men (rate ratio $=0.48,95 \%$ confidence interval 0.38 to 0.60 ). After age, sex, and admissions for heart disease (including comorbidities) were adjusted for, angiography rates were comparable in the least and most deprived fifths $(1.04,0.87$ to 1.25 ; final goodness of fit statistic $(\mathrm{df}=33)=44 \cdot 2)$.

\section{Discussion}

Using routinely available hospital statistics we have shown that for given levels of hospital admission for heart disease women have less than half the rates of invasive investigation than men. We have also shown that patients from materially deprived areas in Northern Ireland have significantly higher admission rates for ischaemic heart disease and for coronary catheterisation than those from more affluent areas. In view of the known geographical clustering of multiple risk factors for heart disease in poorer areas this pattern is hardly surprising. ${ }^{1314}$ However, after allowing for differential admission rates for ischaemic heart disease we have been unable to show the significantly higher utilisation of coronary catheterisation among the "better off" that has been described in American reports. Our findings nevertheless require some qualification given the shortcomings that pertain to 


\section{Practice implications}

- Referral rates for angiography vary significantly throughout Britain

- The chances of undergoing invasive cardiological assessment depend not only on a patient's clinical presentation but on discretion exercised by specialists

- The lower rates of coronary catheterisation among women warrant further study and may be a worthwhile subject for medical audit

studies that use only routinely available hospital statistics.

Though our ability to assign an area code to the records compares favourably with the completeness of other similar studies, the absence of an electoral ward code for $7-10 \%$ of records may have biased our sample. More complete data on all coronary catheterisations would undoubtedly have been available from the two catheterisation laboratory registers, but it is unlikely that records "captured" by the routine hospital statistics would have been differentially related to patient's sex or to postcode and thence to the relative "affluence" of the catchment population.

At a very basic level the divergence of these results from those of similar American studies of the effect of socioeconomic factors on angiographic investigation could be explained by the obvious differences in the provision of medical services and the absence of universal health care in the United States. Even in the United Kingdom, however, variation in discretionary decisions to admit for myocardial infarction ${ }^{15}$ and in the use of angiography for ischaemic heart disease ${ }^{16}$ is thought to explain an appreciable proportion of the variation in hospital utilisation for these conditions. The sort of analysis used in this study is obviously susceptible to the "ecological fallacy" if it turned out that relatively well off patients from the poor areas were the ones referred for angiography. Nevertheless the method has been considered to be relatively robust, ${ }^{17}$ and significant associations between measures of material deprivation and ill health have been shown both at area and at individual levels. . $^{18-20}$

Our findings are at variance with those reported by Finlay et al, who showed that, considering their lower death rates from ischaemic heart disease, the more affluent areas in Greater Glasgow had excess usage of coronary angiography than did the poorer areas. ${ }^{21}$ Their overall pattern was not formally statistically tested, however, and, the use of hospital discharge rates in the present study rather than death rates may more closely represent the population eligible for catheterisation or angiography.

Our findings shed some light on recent claims that women in Britain are discriminated against in their access to revascularisation. ${ }^{5}$ Petticrew et al found significantly lower revascularisation rates for women but were unable to conclude that this reflected differences in referral rates for investigation or for treatment. Our study (which has adjusted for comorbidities, as in the Petticrew study) would lend support to the finding of lower rates for women, but this conclusion must be viewed with caution. ${ }^{22}$ The pattern of clinical presentation ${ }^{23}$ and disease progression of ischaemic heart disease seem to differ in the two sexes. ${ }^{24-26}$ What is required are further studies of the sort undertaken in Trent, ${ }^{815}$ preferably involving the collection of detailed data on treatment intensity at each stage of the referral pathway (from patient to general practitioner, to cardiologist, to surgeon). Only with these sorts of data ${ }^{27}$ might important differences emerge in the treatment of men and women and of materially deprived and affluent groups in our population. Such a study is currently underway.

We thank the Regional Information Branch of the Department of Health and Social Services for the provisional release of data on hospital admissions. The conclusions are those of the authors alone. Thanks are also due to Dr Chris Patterson for statistical advice.

1 Park RE, Fink A, Brook RH, Chassin MR, Kahn KI, Merrick NJ, et al. Physician ratings of appropriate indications for three procedures: theoretical indications vs indications used in practice. Am f Prublic Health 1989;79: 445-7.

2 Chassin MR, Kosecoff J, Solomon D, Brook RH. How coronary angiography is used. Clinical determinants of appropriateness. भAMA 1987;258:2543-7.

3 Bernstein S, Hilborne LH, Leape LI, Fiske ME, Park RE, Kamberg CJ et al. The appropriateness of use of coronary angiography in New York state. f $A M A$ 1993;269:766-9.

4 Elder AT, Shaw TRD, Turnball CM, Starkey IR Elderly and younger patients selected to undergo coronary angiography. BMf 1991;303:950-3.

5 Petticrew M, McKee M, Jones J. Coronary artery surgery: are women discriminated against? $B M$ F $^{1993 ; 306: 1164-6 .}$

6 Bobbio M, Detrano R, Shandling AH, Ellestad MH, Clark J, Bresden O, et al. Clinical assessment of the probability of coronary artery disease: judgement bias from personal knowledge. Med Decis Making 1992;12:197-203.

7 Tofler GH, Muller JE, Stone PH, Davies G, Davis VG, Braunwald E. Comparison of long-term outcome after acute myocardial infarction in patients never graduated from high school with that in more educated patients never graduated from high

8 Tunis SR, Bass EB, Klag M, Steinberg EP. Variation in utilisation of procedures for treatment of peripheral arterial disease. Arch Interm Med procedures for

9 Gray D, Hampton JR, Bernstein SJ, Kosecoff J, Brook RH. Audit of coronary angiography and bypass surgery. Lancet 1990;335:1317-20.

10 Regional Strategic Framework for the Health and Personal Social Services in Northerm Ireland, 1992-97. Belfast: Department of Health and Social Services, 1992.

11 Williams RB, Barefoot JC, Califf RM, Haney TL, Saunders WB, Pryor DB, et al. Prognostic importance of social and economic resources among medically treated patients with angiography. $F A M A$ 1992;267:520-4.

12 Townsend $P$, Phillimore $P$, Beattie $A$. Health and deprivation: inequality and the north. London: Croom Helm, 1988.

13 Crombie IK, Smith WCS, Tavendale R, Tunstall-Pedoe H. Geographical clustering of risk factors and lifestyle for coronary disease in the Scotrish heart health study, Br Hear ₹ 1990;64:199-203.

14 Crombie IK, Kenicer MB, Smith WCS, Tunstall-Pedoe H. Unemployment, socioenvironmental factors and coronary heart disease in Scotand. Br Heart f 1989;61:172-7.

15 Price CE, Paul EA, Bevan RG, Holland WW. Equity and medical practice variation: relationships between standardised discharge ratios in total an for selected conditions in English districts. $f$ Epidemiol Community Health 1992;46:58-62.

16 Bernstein SJ, Kosecoff J, Gray D, Hampton JR, Brook RH. The appropriateness of the use of cardiological procedures. Int $\mathcal{f}$ Technol Assess Health Care 1993;9:3-10.

$17 \mathrm{Kreiger}$ N. Overcoming the absence of socioeconomic data in medical records: validation and application of a census-based methodology. Am $\mathrm{f}$ Public Health 1992;92:703-10.

18 Spatial and social variations in the distribution of health indicators in Norther Ireland. Belfast: Policy Research Institute, Queen's University, 1990.

19 Curtis SE. Use of survey data and small area statistics to assess the link between individual morbidity and neighbourhood deprivation. If Epidemiol Community Health 1990;44:62-8.

20 Mays N, Chinn S. Relation between all cause standardised mortality ratios and two indices of deprivation at regional and district level in England. f Epidemiol Community Health 1989;43:191-9.

21 Findlay IN, Dargie HJ, Dyke T. Coronary angiography in Glasgow: relation to coronary heart disease and social class. Br Heart $f$ 1991;66:70.

22 Bickell NA, Pieper KS, Lee KI, Mark DB, Glower DD, Pryor DB, et al. Referral patterns for coronary artery disease treatment: gender bias or good clinical judgement? Ann Interm Med 1992;116:791-7.

23 Garber CE, Carlton RA, Heller CV. Comparison of Rose questionnaire angina to exercise thallium scintigraphy: different findings in males and females. to elin Epidemiol 1992;45:715-20.

24 Lerner DJ, Kannel WB. Patterns of coronary heart disease morbidity and mortality in the sexes: a 26 year follow-up of the Framingham population. Am Heart $f$ 1986;111:383-90.

25 Feibach NH, Viscoli CM, Horwitz RI. Differences between women and men in survival after myocardial infarction. Biology or methodology? $\mathscr{Y} A M A$ 1990;263:1092-6.

26 Orencia A, Bailey K, Yawn B, Kottke T. Effect of gender on long term outcome of angina pectoris and myocardial infarction/sudden unexpected death. FAMA 1993;269:2392-7.

27 Sox H, Hickam D, Marton K, Moses L, Skeff KM, Sox CH, et al. Using the patient's history to estimate the probability of coronary artery disease: a comparison of primary care and referral practices. Am FMed 1990;89:7-14.

(Accepted 26 August 1993) 